\title{
Regularities of Changes in the Microhardness of Carbon Steels during Gas Laser Cutting
}

\author{
Igor V. Minaev ${ }^{1}$, Evgeny V. Ageev², Sergey N. Kutepov ${ }^{1}$, and Alexander E. Gvozdev ${ }^{\text {* }}$ \\ ${ }^{1}$ Tula State Pedagogical University by Leo Tolstoy, Tula \\ ${ }^{2}$ Southwest State University, Kursk
}

\begin{abstract}
The paper considers the regularities of changes in the microhardness of carbon steels during gas-laser cutting. Quantitative numerical estimates of the extent of the gas-laser thermal influence zone are made. It is shown that according to the data of durometric analysis, the length of the zone of gas-laser thermal influence reaches 2200 microns.
\end{abstract}

\section{Introduction}

At present, the industry widely uses the processes of gas laser cutting (GLC) of metal sheets made of carbon steels for various purposes. At the same time, one of the urgent tasks of modern metallurgy is the problem of studying the structure and properties of metal alloys when exposed to laser radiation. Therefore, identifying the features of changes in the structure and properties of carbon steels during gas-laser cutting allows us to establish the patterns of behavior of metal alloys in extreme conditions and to develop on this basis new resource-saving processing methods. During gas-laser cutting, high-speed heating and cooling of the metal occurs in the surface layers of the cut, as a result of which a zone of gas-laser thermal influence (ZGLTI) is formed. Laser cutting is characterized by a local energetic effect on the material, a high processing speed and a good quality of the resulting surface, as a result of which the ZGLTI with a modified structure has a certain thickness.

\section{Materials and methods}

To determine the length of the ZGLTI (L), metallographic studies were used, durometric analysis and microhardness measurements were carried out on both sides of the sample from the surface of the gas-laser cut into the depth of the samples in direction 1 (see Fig. 1) [1].

\footnotetext{
*Corresponding author: dgwozdew.alexandr2013@yandex.ru
} 


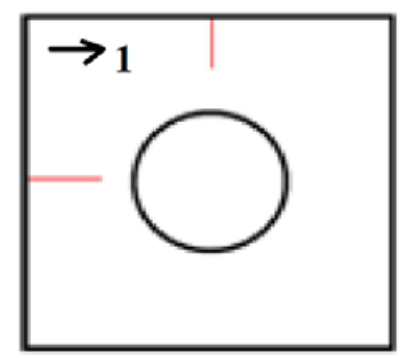

Fig. 1. Schematic representation of the sample and the place of microhardness measurement on the sample (1)

\section{Experimental results and discations}

An analysis of the results obtained [1, 2] on the change in the microhardness of the surfaces of the gas-laser thermal influence zones showed that the nature of the change in the microhardness for all samples of the studied steels is similar: the highest values are determined near the cut surface, then HV gradually decreases until reaching the value characteristic of the initial state. On some samples, a repeated increase in microhardness was revealed. The obtained values of $\mathrm{L}$ are shown in the table 1.

Table 1. Length of zones of gas-laser thermal influence of steels [2]

\begin{tabular}{|c|c|c|c|c|c|c|}
\hline \multirow[b]{2}{*}{ Material } & \multirow{2}{*}{$\begin{array}{c}\text { Thickness, } \\
\text { mm }\end{array}$} & \multirow[b]{2}{*}{ Power W, } & \multirow{2}{*}{$\begin{array}{l}\text { Speed V, } \\
\mathrm{mm} / \mathrm{min}\end{array}$} & \multicolumn{3}{|c|}{$\begin{array}{l}\text { Length of the zone of gas-laser } \\
\text { thermal influence L, mm }\end{array}$} \\
\hline & & & & $\begin{array}{l}\text { From the } \\
\text { side of } \\
\text { zone } 1\end{array}$ & $\begin{array}{l}\text { From the } \\
\text { side of } \\
\text { zone } 2\end{array}$ & $\begin{array}{c}\text { Average } \\
\text { of two } \\
\text { zones }\end{array}$ \\
\hline \multirow{4}{*}{ Steel 20} & \multirow{4}{*}{6} & 890 & 1200 & 1,4 & 2,0 & 1,7 \\
\hline & & 890 & 1000 & 1,8 & 2,0 & 1,6 \\
\hline & & 990 & 1200 & 1,9 & 1,2 & 1,55 \\
\hline & & 1090 & 1400 & 2,0 & 2,0 & 2,0 \\
\hline \multirow{4}{*}{ Steel 35} & \multirow{4}{*}{6} & 1100 & 1200 & 2,0 & 2,4 & 2,2 \\
\hline & & 900 & 1200 & 2,0 & 2,0 & 2,0 \\
\hline & & 1100 & 1200 & 2,0 & 2,0 & 2,0 \\
\hline & & 1100 & 1200 & 1,4 & 2,0 & 1,7 \\
\hline \multirow{5}{*}{ Steel 45} & \multirow{5}{*}{8} & 900 & 800 & 1,2 & 2,4 & 1,8 \\
\hline & & 1000 & 900 & 2,2 & 2,6 & 2,4 \\
\hline & & 900 & 850 & 2,0 & 2,2 & 2,1 \\
\hline & & 800 & 1000 & 1,8 & 2,2 & 2,0 \\
\hline & & 900 & 1000 & 2,0 & 2,2 & 2,1 \\
\hline \multirow{3}{*}{ Steel 45} & \multirow{3}{*}{10} & 1100 & 1000 & 2,0 & 2,6 & 2,3 \\
\hline & & 900 & 1000 & 2,0 & 2,6 & 2,3 \\
\hline & & 900 & 800 & 1,2 & 1,8 & 2,0 \\
\hline \multirow{2}{*}{ Steel U7 } & \multirow{2}{*}{10} & 800 & 800 & 2,0 & 2,4 & 2,2 \\
\hline & & 750 & 700 & 2,4 & 2,6 & 2,5 \\
\hline \multirow{3}{*}{ Steel U8A } & \multirow{3}{*}{10} & 1400 & 1000 & 2,4 & 1,6 & 2,0 \\
\hline & & 1200 & 700 & 1,6 & 2,4 & 2,0 \\
\hline & & 1200 & 700 & 2,0 & 2,4 & 2,2 \\
\hline
\end{tabular}


From the data given in the table, it is possible to draw ambiguous conclusions that for each steel the dependence of the length of the ZGLTI on the parameters of the GLC is different. So, for example, for steel grade 20, the length of the ZGLTI from the side of the sample adjacent to the laser exposure zone increases, and from the side of the sample adjacent to the zone of gas removal of the melt, it practically does not change, depending on the GLC modes. No dependences of the length of the ZGLTI on the parameters of the GLC have been revealed for steel grade 35 . For grade 45 steel with a sample thickness of 8 $\mathrm{mm}$, the length of the ZGLTI from the side of the zone of gas removal of the melt increases with increasing power. With an increase in speed, the length of the ZGLTI from the sides of both zones increases. For steel grade 45 with a sample thickness of $10 \mathrm{~mm}$, with an increase in the speed and power, the length of the ZGLTI on the surfaces from the side of the laser action zone increases. For steel grade U7, with an increase in power and speed, the length of the ZGLTI on the surfaces adjacent to both zones decreases. For steel grade U8A, with an increase in speed and power, the length of the ZGLTI from the side of gas removal of the melt decreases [2-5].

\section{Conclusion}

An analysis of the results of experimental studies showed that the nature of the change in microhardness for all samples of the studied steels is the same: the highest values are achieved near the surface of the gas-laser cut and are, for example, for steel $20-350 \mathrm{HV}$, and for steel U8A - $540 \mathrm{HV}$, which is more than $2.5 \ldots 2.7$ times the initial microhardness of these steels, after which HV gradually decreases. The performed quantitative numerical estimates of the length of the gas-laser thermal influence zone made it possible to establish that the length of the gas-laser thermal influence zone reaches 2200 microns [2, 3].

\section{References}

1. Minaev I.V. Features of the formation of the structure and properties of carbon structural and tool steels during gas laser cutting: dis. ... Cand. tech. Sciences: 05.16.01 / Minaev Igor Vasilevich. Tula, 2021. 352 p.

2. N.N. Sergeev, I. V. Minaev, I. V. Tikhonova, S.N. Kutepov, M. Yu. Komarova, E.S. Alyavdina, A.E. Gvozdev, A.A. Kalinin; ed. prof. N.N. Sergeeva. Fundamentals of laser and gas-plasma processing of steels: monograph. Tula: Publishing house of Tula State University, 2017. 337 p.

3. N.N. Sergeev, I. V. Minaev, A.E. Gvozdev, A.E. Cheglov, I.V. Tikhonova, O.M. Gubanov, I.A. Tsykanov, E.S. Alyavdina, A.D. Brecks. Influence of carbon content and parameters of laser cutting on the structure and length of the heat-affected zone of steel sheets. Steel. 2018. No. 5. S. 21-28.

4. Sergeev, I.V. Minaev, I. V. Tikhonova, A.E. Gvozdev, A.G. Kolmakov, A.N. Sergeev, S.N. Kutepov, D.V. Maliy. Methodology for selecting modes of laser cutting of sheets from structural steels to ensure the required set of surface quality indicators. Materials Science. 2019. No. 10. S. 25-32.

5. I.V. Minaev, I.V. Tikhonova, A.E. Gvozdev, A.G. Kolmakov, E.A. Arkhipova. Formation of the Cut Surface and the Surface Hardening of Chain Sprockets Made of St3 and 30KhGSA Steels during Laser Cutting. Russian Metallurgy (Metally). 2021. Vol.2021. No. 4. P.501-506.

6. A.E. Gvozdev, A.G. Kolmakov, A.V. Malyarov, N.N. Sergeev, I.V. Tikhonova, M.E. Prutskov. Conditions for the manifestation of cementite instability during thermal cycling of carbon steels. Materials Science. 2014. No. 10. S. 31-36. 
7. A.M. Adaskin, A.A. Vereshchaka, A.S. Vereshchaka, Study of wear mechanism of hard-alloy tools during machining of refractory alloys, Journal of Friction and Wear, 2013, vol. 34, No. 3, pp. 208-213.

8. V.L. Bibik, Forecasting of hard-alloyed cutting tool resistance based on thermal diffusivity, Materials Science Forum, 2013, vol. 762, pp. 777-781.

9. Nawaz W., Xu S., Huang B., Wu X., Wu Z., Li Y., "Nanotechnology and immunoengineering: how nanotechnology can boost car- $t$ therapy“, Acta Biomaterialia. 2020. No. 109. pp. 21-36.

10. Povarova K.B. Powder Metallurgy of Tungsten Alloys, Proceedings of 3rd EURO PM 2004 Powder Metallurgy World Congress and Exhibition, 2004, No. 5, pp. 106-112.

11. Antsiferova I.V., Esaulova I.A., "Nanotechnology research and education centers as an intellectual basis of nanotechnology in Russia“,Middle East Journal of Scientific Research. 2013. No. 13. pp. 127-131.

12. Occhiutto M.L., Costa V.P., Maranhão R.C., Konstas A.G., "Nanotechnology for medical and surgical glaucoma therapy-a review, Advances in Therapy. 2020. T. 37. No.1. pp. 155-199.

13. Phung C.D., Pham L.M., Jeong J.-H., Yong C.S., Kim J.O., Tran T.H., Nguyen H.T., "Current developments in nanotechnology for improved cancer treatment, focusing on tumor hypoxia“, Journal of Controlled Release. 2020. T. 324. pp. 413-429.

14. Dar A.H., Rashid N., Dar M.A., Majid I., Hussain S., "Nanotechnology interventions in aquaculture and seafood preservation“, Critical Reviews in Food Science and Nutrition“, 2020. T. 60. No. 11. pp. 1912-1921.

15. Desai P., Thumma N.J., Wagh P.R., Zhan S., Wang J., Prabhu S., Ann D., "Cancer chemoprevention using nanotechnology-based approaches",Frontiers in Pharmacology. 2020. T. 11. pp. 323.

16. Choubdar N., Avizheh S., "Nanotechnology based delivery systems of drugs currently used to treat alzheimer’s disease“,Nanoscience and Nanotechnology - Asia. 2020. T. 10. No. 3. pp. 228-247.

17. Khorev,A.I., "Alloying and heat treatment of structural $(\alpha+\beta)$ titanium alloys of high and superhigh strength“, Russian Engineering Research, 2010, vol. 30, No. 7, pp. 682688.

18. E.V. Ageev, R.A. Latypov, Fabrication and investigation of carbide billets from powders prepared by electroerosive dispersion of tungsten-containing wastes, Russian Journal of Non-Ferrous Metals, 2014, vol. 55, No. 6, pp. 577-580.

19. E.V. Ageeva, E.V. Ageev, N.M. Horyakova, Morphology of copper powder produced by electrospark dispersion from waste, Russian Engineering Research, 2014, vol. 34, No. 11, pp. 694-696.

20. E.V. Ageev, R.A. Latypov, E.V. Ageeva, Investigation into the properties of electroerosive powders and hard alloy fabricated from them by isostatic pressing and sintering, Russian Journal of Non-Ferrous Metals, 2015, vol. 56, No. 1, pp. 52-62. 